\title{
Free Peroneal Artery Perforator-Based Flap for Soft Tissue Reconstruction of the Finger
}

\author{
Kenji Kawamura, MD ${ }^{1}$ Hiroshi Yajima, MD ${ }^{1}$ Shohei Omokawa, MD ${ }^{1}$ Takamasa Shimizu, MD ${ }^{1}$ \\ Satoshi Hayashi, MD ${ }^{1}$ Naoki Maegawa, MD ${ }^{1}$ Yasuaki Nakanishi, MD ${ }^{1}$ Tsutomu Kira, MD ${ }^{1}$ \\ Tadanobu Onishi, MD ${ }^{1}$ Naoki Hayami, MD ${ }^{1}$ Hideo Hasegawa, MD ${ }^{1}$ Yasuhito Tanaka, MD ${ }^{1}$
}

1 Department of Orthopaedic Surgery, Nara Medical University,

Address for correspondence Kenji Kawamura, MD, Department of Nara, Japan

Orthopaedic Surgery, Nara Medical University, 840 Shijo-cho,

J Reconstr Microsurg Open 2017;2:e136-e139.

Kashihara, Nara 634-8522, Japan (e-mail: kkenji@naramed-u.ac.jp).

\begin{abstract}
Background The peroneal artery perforator-based flap has been widely used as a pedicled propeller flap for soft tissue reconstruction in the lower extremity; however, its application as a free flap has been rarely reported. We report on the utility of the free peroneal artery perforator-based flap for finger soft tissue reconstruction.

Methods Twelve patients underwent reconstructions of soft tissue defects of the finger with free peroneal artery perforator-based flaps. The soft tissue defects were located either dorsally and/or laterally on the fingers. The size of the flaps ranged from $5 \times 2$ to $8 \times 3 \mathrm{~cm}$. The length of the vascular pedicles ranged from 4 to $5 \mathrm{~cm}$. The artery and vein of the perforator vessels were anastomosed in the finger to the digital artery and subcutaneous vein, respectively.

Results All twelve flaps survived completely, and the donor site in the lower leg was closed primarily in all cases. Secondary defatting was performed in six cases, while in the remaining cases, thinning of the flap was performed when the flap was transferred. Conclusion The advantages of the free peroneal artery perforator-based flap for

\section{Keywords}

- perforator flap

- peroneal artery perforator-based flap

- finger reconstruction finger soft tissue reconstruction include the following: the flap is flexible and can be thinned to match the texture of the finger; elevation of the flap is easy; the donor site can be closed primarily; there is no need to sacrifice any main arteries in the lower leg; and the diameter of the perforator vessels is suitable for anastomosis to the digital artery and subcutaneous vein in the finger.
\end{abstract}

The peroneal flap as reported by Yoshimura in 1984 is nourished by skin perforator vessels arising from the peroneal artery and concomitant veins and can be harvested from the lateral lower leg. ${ }^{1}$ The peroneal flap is now called the peroneal artery perforator flap. ${ }^{2-4}$ Yoshimura originally described that the vascular pedicle of the peroneal flap was composed of the peroneal artery and concomitant veins. A disadvantage of the peroneal flap is that it requires sacrificing the peroneal artery, which is one of the three main arteries in the lower leg. The recent development of perforator flaps has dramatically changed soft tissue reconstructive surgery. The use of perforator flaps enables surgeons to

received

September 21, 2017

accepted

September 28, 2017
DOI https://doi.org/

$10.1055 / \mathrm{s}-0037-1608670$. ISSN $2377-0813$. minimize donor-site morbidity by preserving important tissues, including the muscle and the major vessels. ${ }^{5-7}$ The peroneal artery perforator-based flap, which utilizes only perforator vessels for the vascular pedicle, is minimally disruptive to the donor site because there is no need to sacrifice any major arteries of the lower leg. Although the peroneal artery perforator-based flap has been widely used as a pedicled propeller flap for soft tissue reconstruction in the lower extremity, ${ }^{8,9}$ free peroneal artery perforator-based flap transfer has been rarely reported. ${ }^{10}$ In this article, we report on the utility of the free peroneal artery perforatorbased flap for soft tissue reconstruction of the finger.
Copyright $\odot 2017$ by Thieme Medical Publishers, Inc., 333 Seventh Avenue, New York, NY 10001, USA. Tel: +1(212) 584-4662.
License terms

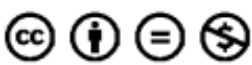




\section{Methods}

Between 2000 and 2016, twelve patients who had soft tissue defects of the finger underwent reconstruction with a free peroneal artery perforator-based flap. There were 10 men and 2 women, and their ages at the time of the surgery ranged from 19 to 60 years (mean of 48 years). The soft tissue defects were caused by trauma in all cases and were located on the dorsal and/or lateral sides of the fingers. Six cases involved the index finger, four the middle finger, two the ring finger, and one the little finger. The size of the skin defects ranged from $4 \times 2$ to $7 \times 3 \mathrm{~cm}$. Before harvesting the free peroneal artery perforator-based flap, the location of the perforator vessels arising from the peroneal artery was plotted using a Doppler flowmeter. There were often multiple (two to five) points in the distal and middle third of the lateral lower leg along the posterior margin of the fibula. The flap was designed to include these points. The first incision was made along the posterior border of the flap. The skin perforator vessels that passed through the muscle septum between the soleus and peroneal muscles were easily located. After confirming the perforator vessels, the flap was elevated anteriorly. The dissection of the perforator vessels was then performed toward the peroneal artery and concomitant veins with ligation of the muscular and fibular branches. The free peroneal artery perforator-based flap was elevated to ligate the perforator vessels at the bifurcation from the peroneal vessels. The size of the flaps ranged from $5 \times 2$ to $8 \times 3 \mathrm{~cm}$. The length of the vascular pedicles ranged from 4 to $5 \mathrm{~cm}$. The artery and vein of the perforator vessels were anastomosed in the finger to the digital artery and subcutaneous vein, respectively.

\section{Results}

All flaps survived completely. The donor site in the lower leg was closed primarily in all cases. There have been no donorsite problems. Secondary defatting of the grafted flap was performed in 6 of the 12 cases at 3 to 5 months after the flap surgery. In other cases, thinning of the flap was performed when the flap was transferred. All the patients were satisfied with their results.

\section{Case Reports}

\section{Case 1}

A 48-year-old woman had a skin defect on the radial side of

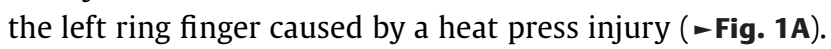
An $8 \times 3 \mathrm{~cm}$ peroneal artery perforator-based flap was harvested from the right lower leg to cover the skin defect (-Fig. 1B). The thinning of the flap was performed before ligation of the vascular pedicle. The length of the vascular pedicle was $5 \mathrm{~cm}$. The donor site was closed primarily (-Fig. 1C). The perforator artery was anastomosed to the digital artery, and the vein was anastomosed to the subcutaneous vein in the finger. The flap survived completely and adapted well in appearance (-Fig. 1D).

\section{Case 2}

A 38-year-old man had a skin defect on the radial side of the left middle finger caused by a crush injury ( - Fig. 2A). A $5 \times 2 \mathrm{~cm}$ peroneal artery perforator-based flap was harvested from the right lower leg (-Fig. 2B), and the length of vascular pedicle was $4 \mathrm{~cm}$. The donor site was closed primarily. The perforator artery was anastomosed to the digital artery, and the vein was anastomosed to the subcutaneous vein in the finger. The flap survived completely (-Fig. 2C). Secondary defatting was performed at 3 months after the flap surgery, and the flap adapted well in appearance (-Fig. 2D).

\section{Discussion}

The concept of the perforator flap developed after the first report of a deep inferior epigastric artery perforator flap by Koshima and Soeda in $1989 .^{5}$ It had been believed that vascularity of the skin flap depended on the underlying rectus abdominis muscle, but Koshima and Soeda proved that the skin flap could be nourished by just a single perforator vessel without going underneath the muscle. A variety of perforator flaps have since been developed from various sites of the body ${ }^{6-8}$ The most important feature of perforator flaps is that these are minimally invasive to the donor site. Perforator flaps can preserve not only the underlying muscle but also the main arteries in the extremities. In 1991, the concept of the perforator-based propeller flap was introduced by Hyakusoku and colleagues. ${ }^{11}$ Perforator-based propeller flaps are versatile local island flaps based on a single dissected perforator vessel and designed to rotate up to 180 degrees to cover adjacent skin defects. The peroneal artery perforator-based propeller flap has been widely used for soft tissue reconstruction in the lower extremity. 8,9

A free perforator-based flap, sometimes called a free true perforator flap, ${ }^{12}$ has been only rarely reported because the small diameter of the perforator vessels makes vascular anastomosis difficult at the recipient site. ${ }^{10}$ According to previous anatomical studies, ${ }^{13-15}$ the average diameter of the perforator vessels arising from the peroneal artery is approximately $1 \mathrm{~mm}$. The diameter of the perforator vessels is suitable for end-to-end anastomosis to the digital artery and subcutaneous veins in the finger. The mean length of the perforators from the peroneal artery was approximately $5 \mathrm{~cm}$, which is adequate for the vascular pedicle of the flap in finger reconstruction. The other advantages of the free peroneal artery perforator-based flap for finger soft tissue reconstruction include the following: the flap is flexible and can be thinned to match the texture of the finger, elevation of the flap is easy when the septocutaneous perforator is dissected, and the donor site can be closed primarily with less than $3 \mathrm{~cm}$ in width. However, there are a few disadvantages of the free peroneal artery perforator-based flap for finger soft tissue reconstruction. The skin of the flap may be hairy in men. If the patient dislikes hairy skin on the reconstructed finger, hair removal may be necessary. The flap may be bulky in obese individuals. Primary thinning of the flap is possible if the patient and surgeon want to avoid secondary defatting. However, careful thinning must 


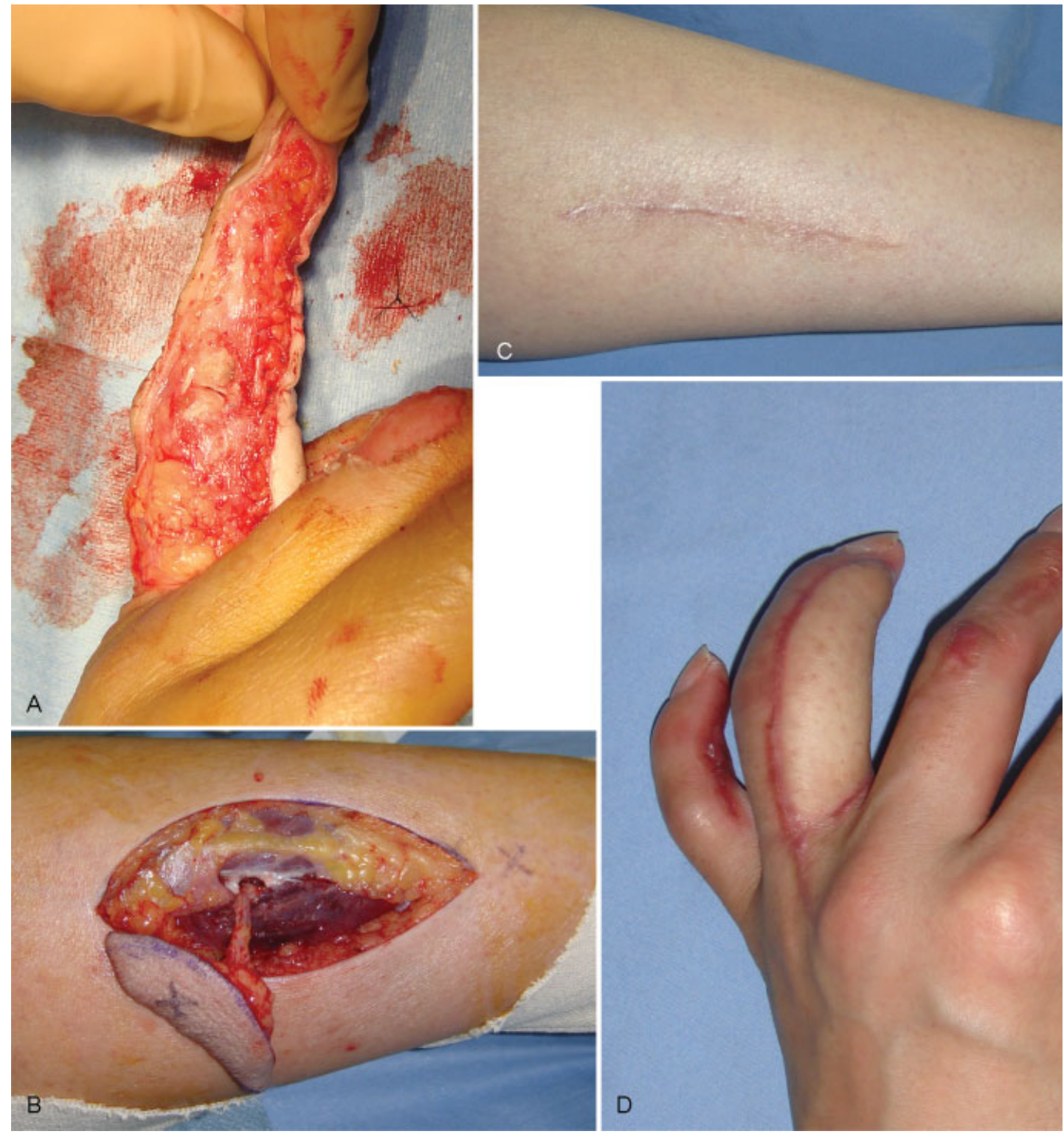

Fig. 1 Case 1 (A) There was a skin defect on the radial side of the ring finger. (B) An $8 \times 3 \mathrm{~cm}$ peroneal artery perforator-based flap with a 5-cm vascular pedicle was harvested. (C) The donor site was closed primarily. (D) At 1 month postoperatively, the flap survived uneventfully.
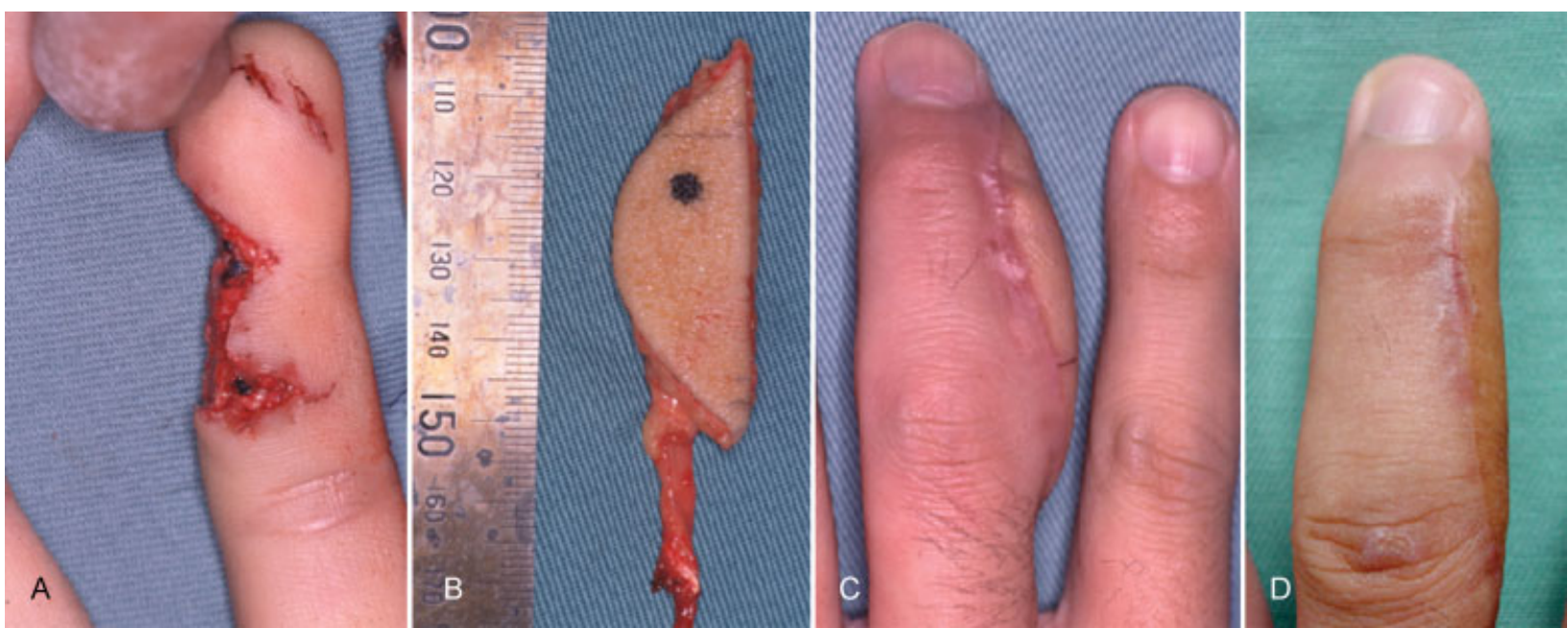

Fig. 2 Case 2 (A) There was a skin defect on the radial side of the middle finger. (B) A $5 \times 2 \mathrm{~cm}$ peroneal artery perforator-based flap with a 4-cm vascular pedicle was harvested. (C) At 3 months postoperatively, the grafted flap was bulky. (D) After secondary defatting, the flap adapted well and survived. 
be performed because damage to the subcutaneous vascular plexus may cause flap necrosis. Secondary defatting is a safe and reliable procedure. The skin of the lateral lower leg is soft and flexible, which is not suitable as the graft for the palmar side of the finger. Finally, the free peroneal artery perforatorbased flap cannot restore sensation. For these reasons, a free peroneal artery perforator-based flap should be applied to defects on the dorsal and/or lateral sides of the finger.

\section{Conclusion}

The peroneal artery perforator-based flap is minimally disruptive to the donor site and is suitable for soft tissue reconstruction of the finger in cases with soft tissue defects on the dorsal and/or lateral sides of the finger.

\section{Conflict of Interest}

None.

\section{References}

1 Yoshimura M, Imura S, Shimamura K, Yamauchi S, Nomura S. Peroneal flap for reconstruction in the extremity: preliminary report. Plast Reconstr Surg 1984;74(03):402-409

2 Acartürk TO, Maldonado AA, Ereso A. Intraoral reconstruction with "thinned" peroneal artery perforator flaps: an alternative to classic donor areas in comorbid patients. Microsurgery 2015;35 (05):399-402

3 Baj A, Beltramini GA, Demarchi M, Giannì AB. Extended-pedicle peroneal artery perforator flap in intraoral reconstruction. Acta Otorhinolaryngol Ital 2013;33(04):282-285
4 Wolff KD, Bauer F, Wylie J, Stimmer H, Hölzle F, Kesting M. Peroneal perforator flap for intraoral reconstruction. Br J Oral Maxillofac Surg 2012;50(01):25-29

5 Koshima I, Soeda S. Inferior epigastric artery skin flaps without rectus abdominis muscle. Br J Plast Surg 1989;42(06):645-648

6 Koshima I, Moriguchi T, Ohta S, Hamanaka T, Inoue T, Ikeda A. The vasculature and clinical application of the posterior tibial perforator-based flap. Plast Reconstr Surg 1992;90(04):643-649

7 Angrigiani C, Grilli D, Siebert J. Latissimus dorsi musculocutaneous flap without muscle. Plast Reconstr Surg 1995;96(07): 1608-1614

8 Shen L, Liu Y, Zhang C, et al. Peroneal perforator pedicle propeller flap for lower leg soft tissue defect reconstruction: Clinical applications and treatment of venous congestion. J Int Med Res 2017;45(03):1074-1089

9 Ahn DK, Lew DH, Roh TS, Lee WJ. Reconstruction of ankle and heel defects with peroneal artery perforator-based pedicled flaps. Arch Plast Surg 2015;42(05):619-625

10 Kawamura K, Yajima H, Kobata Y, Shigematsu K, Takakura Y. Clinical applications of free soleus and peroneal perforator flaps. Plast Reconstr Surg 2005;115(01):114-119

11 Hyakusoku H, Yamamoto T, Fumiiri M. The propeller flap method. Br J Plast Surg 1991;44(01):53-54

12 Yabe T, Takahashi M, Kamano M. The free true perforator flap. J Reconstr Microsurg 2007;23(06):329-333

13 Yoshimura M, Shimada T, Hosokawa M. The vasculature of the peroneal tissue transfer. Plast Reconstr Surg 1990;85(06):917-921

14 Yajima $H$, Ishida $H$, Tamai S. Proximal lateral leg flap transfer utilizing major nutrient vessels to the soleus muscle. Plast Reconstr Surg 1994;93(07):1442-1448

15 Hupkens P, Schijns W, Van Abeelen M, Kooloos JG, Slater NJ, Ulrich DJ. Lateral lower leg perforator flaps: an anatomical study to localize and classify lateral lower leg perforators. Microsurgery 2015;35(02):140-147 